\title{
Development of multi-function CNC system for teaching based on virtual prototype technology
}

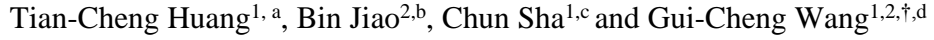 \\ ${ }^{1}$ School of Mechanical Engineering, Nantong Institute of Technology, \\ Nantong Jiangsu 226002,P.R. China \\ ${ }^{2}$ School of Mechanical Engineering, Jiangsu University, \\ Zhenjiang Jiangsu 212013,P.R.China \\ ahuangtc2000@163.com, bbjiao@ujs.edu.cn, ${ }^{c} c s h a @ 163 . c o m$, \\ dwgch@ujs.edu.cn
}

\begin{abstract}
This paper presents a new Computer Numerical Control (CNC) system which can be applied to teaching demonstration. The overall design features of the CNC system are systematically expounded and the application of virtual prototype in the development of multi-function system is introduced, which comes to the harmony and unity by ergonomics. The working state of multi-function system is given, including turning, milling, plane grinding and cylindrical grinding. According to the requirements of theoretical teaching and practical training, assistant teaching devices are added. At last, the physical prototype was constructed and has been used by test.
\end{abstract}

Keywords: Virtual prototype; Multi-function processing; Teaching system.

\section{Introduction}

With the development of advanced manufacturing technology, the product category increases continuously, production lot-sizing continues to decrease, product structure becomes more and more complex, and product high additional value is increasingly deepening, the single mechanical processing mode cannot meet the actual production requirements, often need to process fusion and even composite processing. On the cultivation of application oriented talents of mechanical specialty, most engineering universities and colleges in the $\mathrm{NC}$ teaching still remain in a single processing machine, of different machining methods and machining mechanism to compare and distinguish and could not be functionally composite. In addition, different processing methods (turning, milling, planning, grinding, drilling, etc.) need different types of machine tools, resulting in increased investment costs; the corresponding also resulted in a larger area. Therefore, in order to meet the needs of the development of machinery 
industry, in the field of mechanical application technology teaching, it is urgent to need a kind of multi-function CNC system for teaching.

Virtual prototyping technology is a performance based on concurrent engineering, simulation engineering, intelligent design technology and network information technology, advanced manufacturing technology, it in product design and development process, to establish a product in the computer virtual model, carries on the simulation analysis, forecast products, and the design scheme of evaluation and optimization, in order to finalize the design product production and the ultimate purpose of [1]. Figure 1 is the application of virtual prototyping technology in the process of product development.

\section{The Overall Design of the Multi-function CNCSystem for Teaching}

The design idea of the multi-function CNC system for teaching is to realize turning, milling, drilling, grinding and so on. According to the mechanical structure design of the NC machine tool [2], and the structure characteristics of the machine tool at home and abroad.

Fig. 2 is the overall configuration scheme of Multi-function CNC teaching system, the system in one end of the lathe bed is provided with a main shaft box, spindle box is provided with a rotating spindle, spindle end is provided with a hydraulic chuck for fixing a workpiece to be processed, in relative to the chuck of the lathe bed with hydraulic tailstock. Erecting by grinding head through the movement of the grinding head in the bed of the side wall through the column beam erection guide rail, the rail beams are respectively erected side slide and milling head side slide plate, the hydraulic clamping device is fixed on the crossbeam guide rail, the wheel side sliding plate and milling head side slide servo motor driven by a synchronous belt wheel for driving; the side slide through the plane connecting plate erection ontology in NC slide mounted electromagnetic sucker, the control handle and a handle component drives the screw to achieve the grinding head feed movement, plane grinding, milling head side slide plate milling head connecting plate milling head, through the replacement of different tool, milling, drilling, twists and so on many kinds of processing. The bed is arranged on the base for chip discharge tube. The auxiliary device comprises an electromagnetic sucker, power tool turret, cutting device, grinding rack and other auxiliary equipment.

In addition, the crossbeam guide rail is through the column bolted to the lathe bed base and the crossbeam guide rail on the milling head slide and the grinding wheel slide are removably mounted, enhance the system's modular, high reliability, user domain specific function in the system.

Multi-function CNC system for teaching is mainly divided into four major systems, CNC system, and electrical control, hydraulic and mechanical systems. 
Machine parts can be divided into 4 parts: processing module, feed drive module, machine tool foundation module, and auxiliary parts module. From the specific modules.

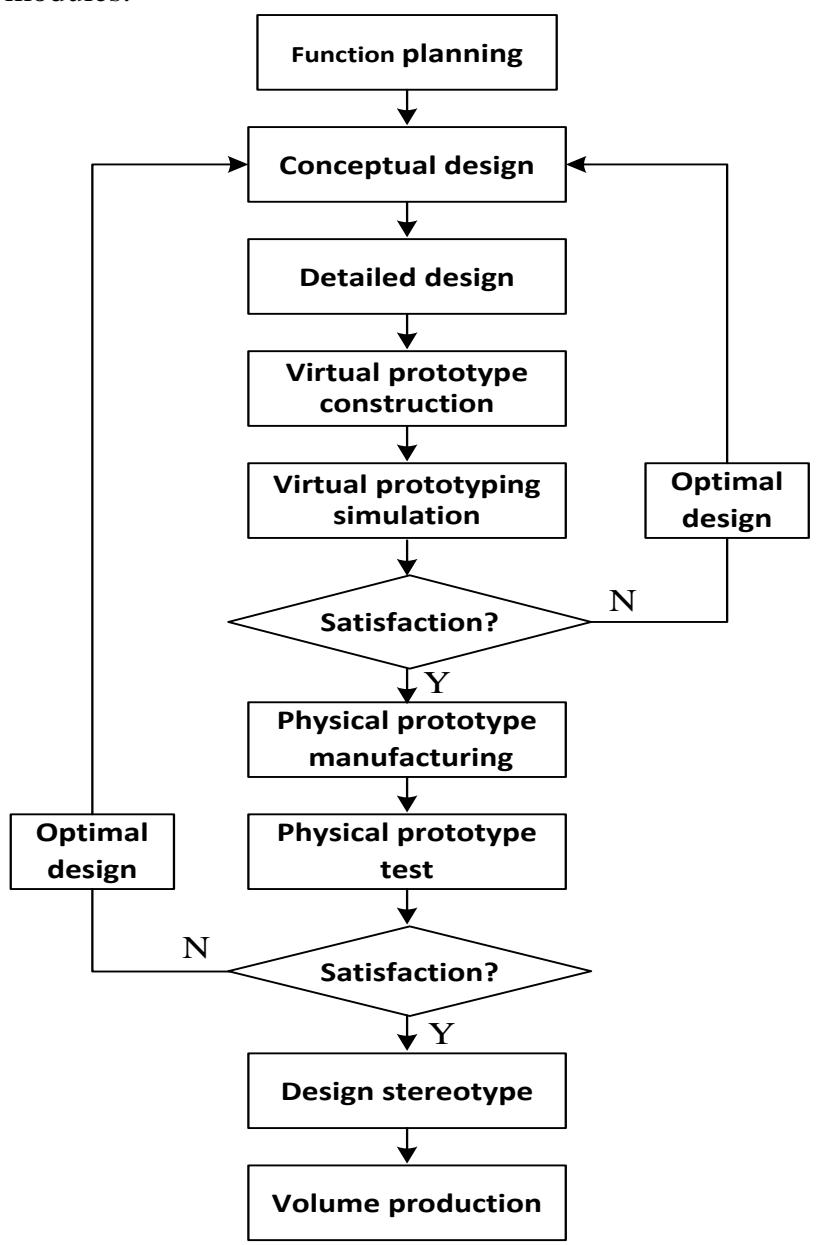

Fig. 1. product development based on Virtual Prototyping Technology 


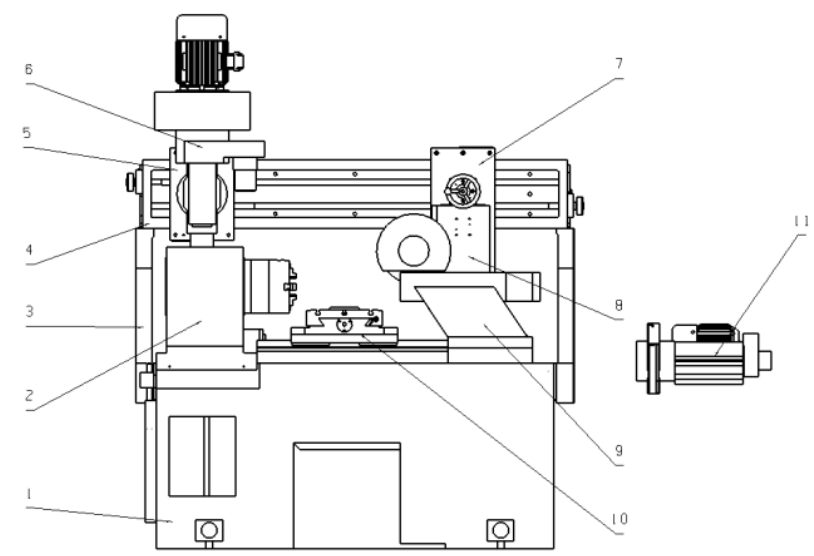

1. Lathe bed base;

2. Headstock;

3. The column;

4. Beam plate;

5. Milling head slide;

6. Milling head;

7 grinding head slide;

8. The grinding head body;

9. Hydraulic tailstock;

10. NC Worktable;

11. Cylindrical grinding frame

Fig. 2 the configuration scheme of the multi-function $\mathrm{CNC}$ system for teaching.

\section{Application of Virtual Prototyping Technology in the Research and Development of Multi-function CNC System for Teaching}

\subsection{Virtual prototyping integrated environment}

The integrated environment of virtual prototype is refers to multiple CAD process, knowledge reasoning process, through (Computer Supported Cooperative Work) CSCW technology, user interface technology, design process management and document technology integration, forming a support for virtual product design integrated simulation environment [4].

At present, the application of the virtual prototype is commonly used in distributed software platform, namely to some has good engineering practice experience of special 3D design and dynamic simulation software as the core, with intermediate conversion program constitute a integrated design and simulation environment [5]. The multi-function teaching system development in the integration of UG software, the financial product design, motion simulation, advanced simulation and information management modules as one [6] can 
provide integration integrated environment for the virtual prototype realization, to make up for the distributed software communication problems in data conversion.

\subsection{Modeling and assembly of the virtual prototype of multi-function CNC teaching system}

The multi-function teaching system structure is complex, which is composed of many parts of machine tool. Virtual modeling technology provides a strong technical support for the structural design of complex parts. Through the UG modeling and virtual assembly module according to the actual size of the parts quickly and accurately establish three-dimensional model, and according to the actual location according to the idea of a bottom-up assembly of virtual assembly, interference checking module using UG, check the parts between the relative position relationship if there is interference. In addition, the man-machine engineering module of UG software was applied, designated parameter to create a model of the human body, by adjusting the parameters to modify the initial design error [7], to ensure that the installation position of the door cover and determine the control panel to meet the requirements of ergonomics. In order to improve the comfort and efficiency of the work, to obtain the best man-machine matching, the environmental factors are also included into the scope of consideration [8].

In addition, the processing system protective cover adopts aluminum alloy molding automatic assembly frame, with transparent toughened glass, not only to meet the safety and also can let the students to watch the processing process, to facilitate the teaching. Figure 3 is the virtual human computer relationship of the Multi-function numerical control teaching system.

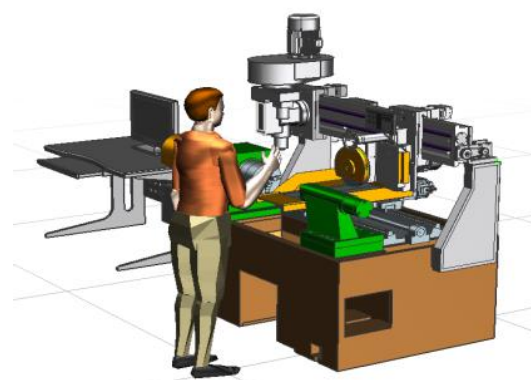

Fig. 3. Man-machine relationship of multi-function CNC system for teaching

\subsection{The finite element analysis of the virtual prototype of multi-function CNC system for teaching}

According to the function planning of the multi-function $\mathrm{CNC}$ system for teaching, the result of the final realization is the process set and the function compound; the mechanical structure is complex, the processing precision is 
difficult to control. In addition, the increase of the processing mode leads to the increase of heat source and operating factors, and the corresponding thermal displacement and operating errors affect the accuracy of the processing [9]. Therefore, it is necessary to carry on the finite element analysis to the Multi-function teaching system, and the overall analysis of the design of the teaching system is to meet the requirements. Using CAE advanced simulation module of UG, the static stiffness and modal analysis of the whole machine are carried out.

The CNC system for teaching of cutting, milling, drilling, cutting, cylindrical grinding and plane grinding and other processing methods, in the process of machining workpiece will generate periodic exciting force. Resonance occurs when the frequency of the exciting force is the same as the natural frequency of the teaching system. Because of the existence of grinding process, the risk coefficient is large, it is necessary to carry on the modal analysis of the key parts of the teaching system and the whole machine. Table 1 Comparison of the frequencies and modes of free mode and constraint mode of the whole machine

Table1. Comparison of frequencies and modes of free mode and constraint mode

\begin{tabular}{c|c|c|c|c|c|c}
\hline \multirow{2}{*}{$\begin{array}{c}\text { workin } \\
\text { g } \\
\text { conditi } \\
\text { on }\end{array}$} & $\begin{array}{c}\text { Freque } \\
\text { ncy /Hz }\end{array}$ & $\begin{array}{c}\text { maximu } \\
\mathrm{m} \\
\text { amplitud } \\
\mathrm{e} / \mathrm{mm}\end{array}$ & $\begin{array}{c}\text { Modal } \\
\text { description }\end{array}$ & $\begin{array}{c}\text { Freque } \\
\text { ncy } / \mathrm{Hz}\end{array}$ & $\begin{array}{c}\text { maximum } \\
\text { amplitude } \\
/ \mathrm{mm}\end{array}$ & $\begin{array}{c}\text { Modal } \\
\text { description }\end{array}$ \\
\hline $\begin{array}{c}\text { The } \\
\text { first } \\
\text { order }\end{array}$ & 29.59 & 0.134 & $\begin{array}{c}\text { The beam and } \\
\text { milling head, } \\
\text { grinding head } \\
\text { plate bend }\end{array}$ & 26.5 & 0.0597 & $\begin{array}{c}\text { Bending of } \\
\text { the column } \\
\text { and beam to } \\
\text { the right }\end{array}$ \\
\hline $\begin{array}{c}\text { The } \\
\text { second } \\
\text { order }\end{array}$ & 31.66 & 0.0563 & $\begin{array}{c}\text { Bending of the } \\
\text { column and } \\
\text { beam to the right }\end{array}$ & 27.9 & 0.123 & $\begin{array}{c}\text { The beam } \\
\text { and milling } \\
\text { head, head } \\
\text { bent }\end{array}$ \\
\hline $\begin{array}{c}\text { The } \\
\text { third } \\
\text { order }\end{array}$ & 79.97 & 0.152 & $\begin{array}{c}\text { Torsion and } \\
\text { downward } \\
\text { slide }\end{array}$ \\
\hline
\end{tabular}

It can be seen from the above table that the frequency and mode of the same structure, under the free and constrained modes, are completely different, because the constraint is applied to change the stiffness of the system. Through the table can be found, the first three orders of frequency is relatively low, when the machine tool dynamic load frequency and the frequency of these several orders will have a lot of vibration, affect the processing accuracy. To reduce the influence of the system dynamic characteristics, the natural frequency of the key 
components can be improved through structural optimization. Fig. 4 is the mode of the whole machine.

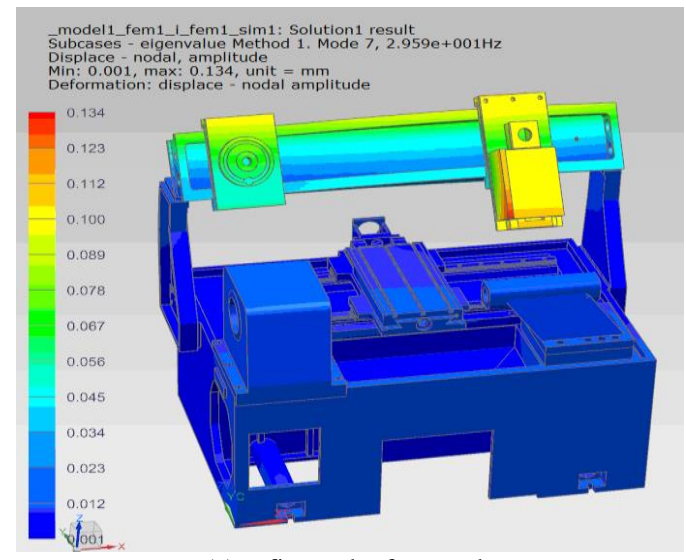

(a) first order free mode

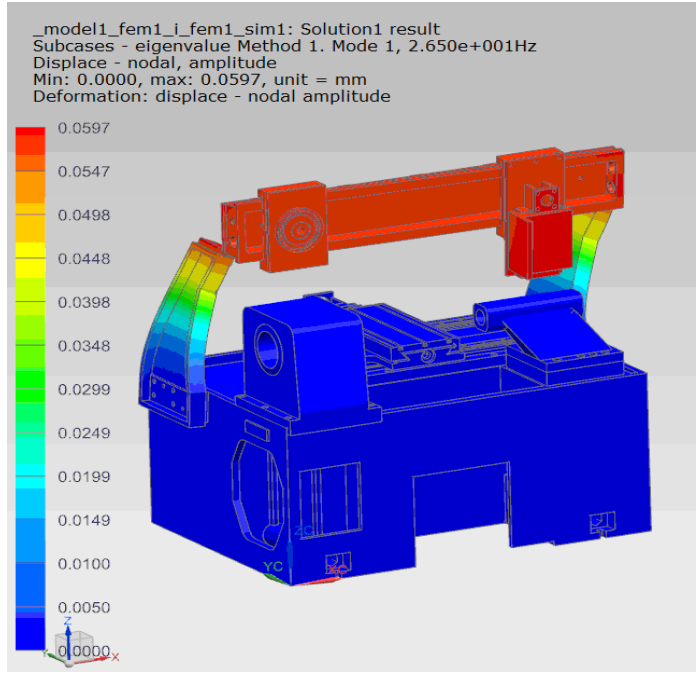

(b) first order constraint mode 


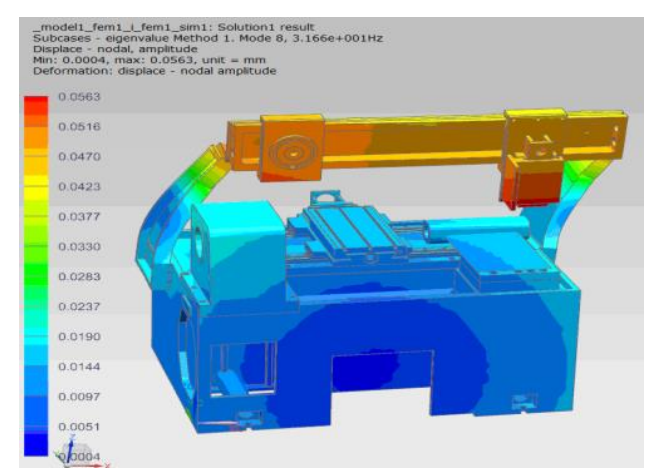

(c) two order free mode

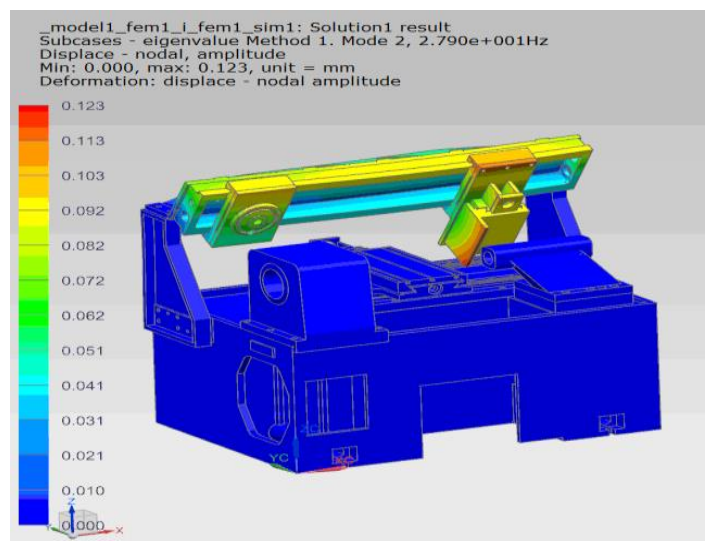

(d) two order constrained mode

Fig.4. the whole modal vibration mode of Multi-function teaching system

\section{The Function Realization of the Multi-function CNC System for Teaching}

\subsection{The working state of the multi-function CNC system for teaching}

Multi-function CNC system for teaching is mainly to achieve the functions of turning, milling, plane grinding and cylindrical grinding, machining range to meet the vast majority of parts of the processing requirements, as shown in Fig. 5. The following is the main working state: 


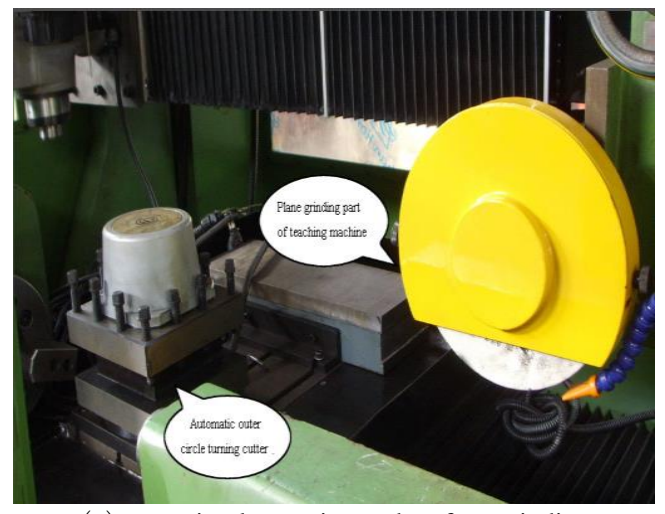

(a) outer circular turning and surface grinding

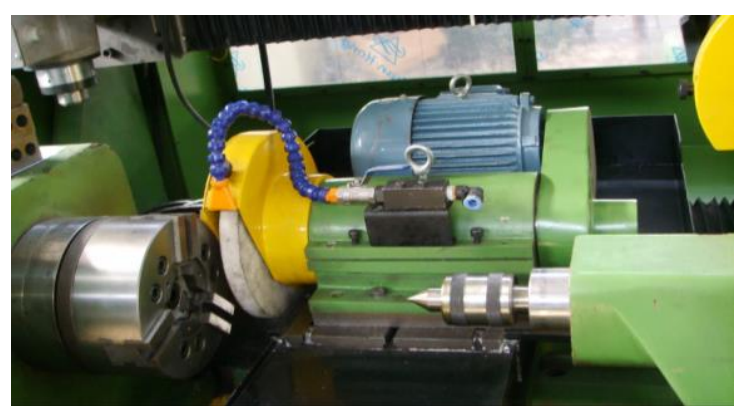

(b) cylindrical grinding

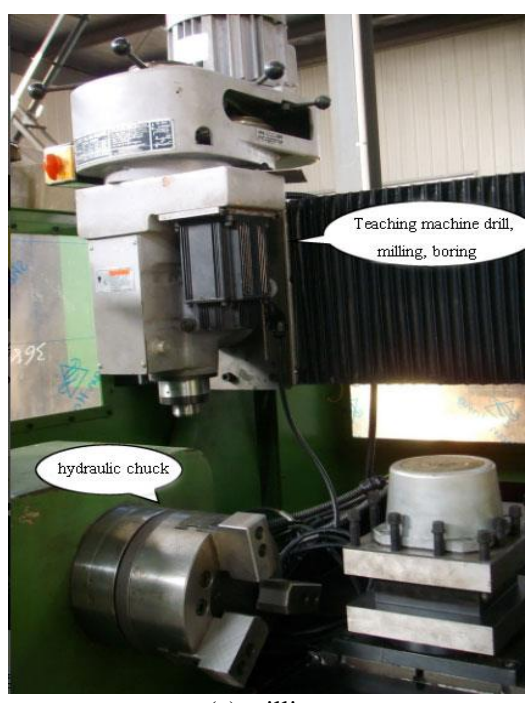

(c) milling

Fig. 5. the working status of the multi-function $\mathrm{CNC}$ system for teaching 
(1) turning (lathe): three jaw chuck through the hydraulic clamp the workpiece, the main motor driven spindle rotation, on the longitudinal slide placing the power turret, turret achieve vertical to the feed, cutting tool workpiece outer circle or end plane.

(2) external cylindrical grinding (cylindrical grinder): with one arm hanging will turn tower turret replaced rack for cylindrical grinding head, rotating spindle and hydraulic tailstock installing thimble, mounted on top of the workpiece, grinding wheel aspect to feed grinding workpiece circular.

(3) the plane grinding, surface grinder): with one arm hanging excircle grinding head holder replacement for rectangular electro-magnetic chuck, chuck adsorption artifacts, motor drive milling head slide to away from the workpiece position, the crossbeam guide rail on the right side of the plane grinding head frame moves to the left into the right position, ceiling plate workpiece longitudinal fast moving, grinding wheel grinding the workpiece surface.

(4) vertical milling machine milling: with one arm hanging will replace the rectangular electro-magnetic chuck for machine vise, motor drive wheel slide to away from the workpiece position, the crossbeam guide rail on the left side of the right of milling headstock move to the right position, the milling head installation tool for milling, drilling and other processing.

\subsection{Teaching device of multi-functional CNC system for teaching}

Multi-function CNC system for teaching will be integrated in a different way of mechanical processing machine tools, to achieve a Multi-task processing functions. In order to facilitate the theoretical teaching and training evaluation, the following teaching devices are added.

(1) Video surveillance system. In order to real-time observation and cutting, milling and grinding process, adding video monitoring system, because the machine has the advantages of compact structure, is not easy to be fixed, coupled with Multi-function CNC machining to produce vibration effect on video quality, so alone produced bending rotation bracket, on the bracket installed directly monitoring system.

(2) Temperature measurement system. In order to solve the inconvenience of machining parameters measurement, the video monitoring system of digital ball machine and digital video recorders, NVR removing, infrared thermography is installed on the bracket. At the same time, with digital and online observation and data processing.

(3) Automatic evaluation system. In order to solve the uncertainty and difficulty of training evaluation by in multi-function CNC teaching system of mechanical structure, electrical control part and hydraulic part of the key parts of the set shift, photo electricity and other sensors, and multi-function teaching 
system automatic evaluation software connected to the real-time automatic scoring.

\section{Conclusions}

(1) To carry on the function plan to the multi-functional CNC system for teaching, and put forward the best configuration scheme. The overall analysis of the mechanical structure of the teaching system is divided into four modules: processing module, feed drive module, machine tool foundation module, and auxiliary parts module.

(2)Through the application of virtual prototyping technology, the development cycle is greatly shortened, the design quality is improved, and the development cost is reduced [10]. The virtual modeling and assembly of Multi-function CNC teaching system is made by using UG integrated software, and the free modal and constrained modal analysis and comparison of the whole machine are carried out. Through physical prototype manufacturing and physical prototype testing, the prototype of a development of stereotypes, products in the fierce market competition to get ahead.

(3) By expand the function of single mechanical processing machine, multi-function $\mathrm{CNC}$ system for teaching can realize turning, milling, plane grinding and cylindrical grinding, adding auxiliary teaching apparatus, from the fundamental theory and practice will combine, meet the contemporary of mechanical application type talents training.

\section{Acknowledges}

This research was supported by the Natural Science Foundation of P.R. China (No.51075192), the National Science and Technology Major Project (ZX201304009031) and Nantong key laboratory (CPI2014002) and Jiangsu province brand professional project (PPZY2015C251).

\section{Reference}

[1]. Xiong Guangleng, Li Bohu, Chai Xudong. System simulation, 2001, (01): 114-117(in Chinese).

[2]. Luo discipline, Xie Fuchun. The principle of NC and NC machine [M]. Beijing: Chemical Industry Press, 2004(in Chinese).

[3]. Zhang Xueling. Static and dynamic characteristics analysis and optimization design of mechanical structure based on generalized modular design [D]. Tianjin University, 2004(in Chinese).

[4]. U.Jasnoch,H.Kress. IFIP Workshop on VP,1994: 11-16. 
[5]. Yang Xiaojing, Fu Zhongyu. Journal of engineering design, the integrated environment UG 2007, (03): 204-209(in Chinese).

[6]. Han Lifen, Ma Qiucheng. UG practical tutorial [M]. Beijing: Mechanical Industry Press, 2001(in Chinese).

[7]. Fu.Jun.The application of virtual prototyping technology in the design and development of XK640 CNC milling machine [D]. Kunming: Kunming University of Science and Technology, 2005(in Chinese).

[8]. Zhou Meiyu. Application of industrial design and ergonomics [M]. Beijing: China Light Industry Press, 2001(in Chinese).

[9]. Shimizu,Shinji.Seimitsu Kogaku Kaishi/Journal of the Japan Society for Precision Engineering,2008,74(4):325-328.

[1]. Jia Zhi, still red, Teng Xiangyang, Chuan bin Wang. China Mechanical Engineering Society special processing branch of 2007 year China (in Chinese). 